\title{
Improved Water Flux of Polyamide Reverse Osmosis Membrane Ontology Doping with g- $\mathrm{C}_{3} \mathrm{~N}_{4}$
}

Feifei Shao ${ }^{1}$, Zhan $\mathrm{Yi}^{1}$, Chunwei $\mathrm{Xu}^{1}$, Liyan $\mathrm{Yu}^{1}$, and Lifeng Dong ${ }^{1,2}$

1. College of Materials Science and Engineering, Qingdao University of Science and Technology, Qingdao 266042, China.

2. Department of Physics, Hamline University, St. Paul 55104, USA.

Seawater desalination technology is one of the most important ways to solve water shortage. Reverse osmosis membrane is the most widely used desalination technology in the world, and polyamide reverse osmosis membrane is the most commonly utilized membrane material. For membrane method, increasing water flux is a critical important research topic since high-water flux not only enables mass production of seawater desalination but also reduce the production cost. Bulk doping modification is one of important methods to improve the flux, and nanomaterials have been extensively investigated as additive materials.

In our experiments, graphitic carbon nitride $\left(\mathrm{g}-\mathrm{C}_{3} \mathrm{~N}_{4}\right)$ was investigated as additive material due to its graphene-like structure and good hydrophilicity. The $\mathrm{g}-\mathrm{C}_{3} \mathrm{~N}_{4}$ was prepared by one step thermal polymerization method. Briefly, urea was heated in a muffle furnace with a heating rate of $5{ }^{\circ} \mathrm{C} / \mathrm{min}$ from $20{ }^{\circ} \mathrm{C}$ to $550{ }^{\circ} \mathrm{C}$ and kept at $550{ }^{\circ} \mathrm{C}$ for $2 \mathrm{~h}$. The sample was cooled down to room temperature, and then it was ground into powder. The polyamide membrane was modified by interfacial polymerization. Firstly, 2 wt. \% m-phenylenediamine (MPD) aqueous solution with different concentrations of $\mathrm{g}-\mathrm{C}_{3} \mathrm{~N}_{4}$ was used to soak polysulfone (PS) membrane for $5 \mathrm{~min}$. After the redundant aqueous solution on the membrane surface was removed, the membrane was soaked by $0.1 \mathrm{wt}$ \% trimesoyl chloride (TMC) organic solution for $60 \mathrm{~s}$ to conduct interfacial polymerization between TMC and MPD. Finally, the modified membrane was obtained.

As shown in Figure 1a, g- $\mathrm{C}_{3} \mathrm{~N}_{4}$ exhibits two-dimensional sheet morphology like graphene and graphene oxide. The morphologies of pristine and modified membranes are demonstrated in Figures. 1b and 1c, respectively. Many typical small cochlear structures can be found in pristine membrane (Figure 1b), and there are variations in the morphology of $\mathrm{g}-\mathrm{C}_{3} \mathrm{~N}_{4}$ modified membranes (Figure 1c). The membrane surface is covered with few $\mathrm{g}-\mathrm{C}_{3} \mathrm{~N}_{4}$ sheets and with significant wrinkles. It is worth noting that the g$\mathrm{C}_{3} \mathrm{~N}_{4}$ modified membrane demonstrates higher water flux than pristine membrane (Figure 1d). Membrane water flux and salt rejection were evaluated using a cross-flow system with $2000 \mathrm{ppm} \mathrm{NaCl}$ feed solution under operating pressure 1.5 MPa. We can see from Figure 1d that water flux is improved with the increase of $\mathrm{g}-\mathrm{C}_{3} \mathrm{~N}_{4}$ concentration. At a concentration of $0.05 \mathrm{~g} / \mathrm{L}$, the flux is $8.0 \mathrm{~L} / \mathrm{m}^{2} \mathrm{~h}$ much higher than $4.3 \mathrm{~L} / \mathrm{m}^{2} \mathrm{~h}$ of pristine membrane. Considering both water flux and salt rejection, $0.01 \mathrm{~g} / \mathrm{L}$ is the optimal concentration for desalination characteristics of the modified membrane with $6.0 \mathrm{~L} / \mathrm{m}^{2} \mathrm{~h}$ water flux and $98.3 \%$ salt rejection. Therefore, the modified membranes doped with $\mathrm{g}-\mathrm{C}_{3} \mathrm{~N}_{4}$ demonstrate obviously improved water flux, and both water flux and salt rejection are enhanced with a concentration of $0.01 \mathrm{~g} / \mathrm{L} \mathrm{g-} \mathrm{C}_{3} \mathrm{~N}_{4}$. 


\section{References:}

[1] F. F. Shao et al, Journal of Membrane Sciences 525 (2017), p.9.

[2] F.F. Shao et al, Desalination 423 (2017), p.21.

[3] This work was financially supported by the National Natural Science Foundation of China (21776147, 61604086 and 21606140), the International Science \& Technology Cooperation Program of China (2014DFA60150). L. F. Dong also thanks financial support from the Malmstrom Endowment Fund at Hamline University.
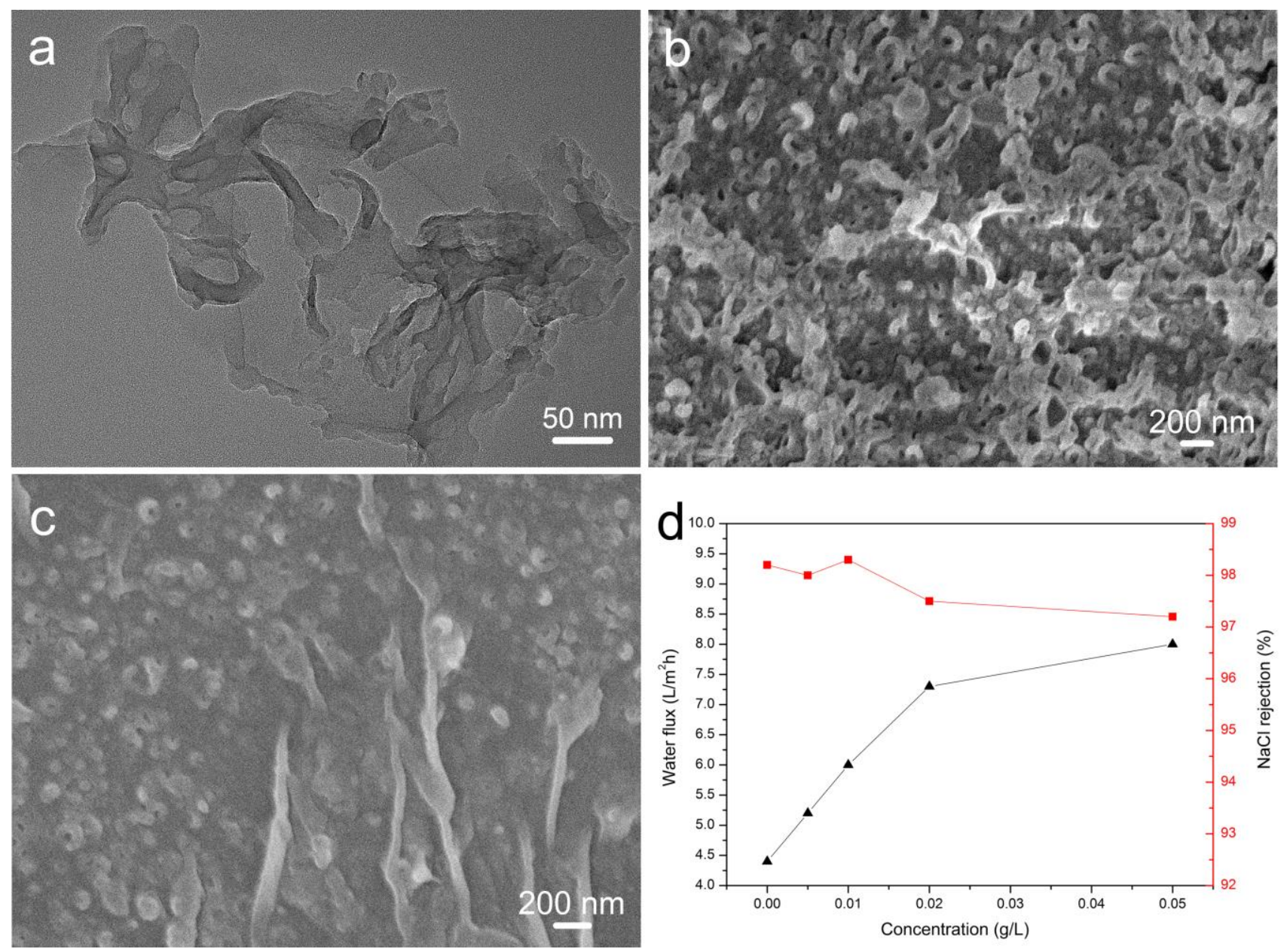

Figure 1. TEM image of $\mathrm{g}-\mathrm{C}_{3} \mathrm{~N}_{4}$ (a), SEM images of pristine (b) and modified polyamide membrane (c), and separation performances of modified polyamide membranes with various $\mathrm{g}-\mathrm{C}_{3} \mathrm{~N}_{4}$ concentrations (d). 